\title{
Significance of MUC4 in Epithelioid Mesothelioma of the Pleura, Adenocarcinoma and Squamous Cell Carcinoma of the Lung (Immunohistochemical Study)
}

\author{
Enas I. Elsayed, Heba H. Ahmed, Taghreed A. Abdelaziz, Samia A. youssef
}

\begin{abstract}
Department of pathology, faculty of medicine, benha university, benha, Egypt.
\end{abstract}

Correspondence to: Heba $\mathrm{H}$. Ahmed, Department of Pathology, Faculty of Medicine, Banha University, Egypt.

Email:

d.heba.hassan999@gmail.com

Received: 18 November 2020

Accepted: 11 September 2021

\begin{abstract}
:
Background: Lung cancer is the second most common cancer, and the leading cause of cancer mortality. Malignant pleural mesothelioma is a highly aggressive malignant neoplasm, and epithelioid mesothelioma is the commonest histological subtype. MUC4 is a high-molecular weight glycoprotein that encoded by MUC4 gene. Aim: The aim of this study was to evaluate MUC4 expression in LAC, LSqCC, and PEM. Materials and Methods: This retrospective study was done upon 70 different lung and pleural lesions designated as; 30 cases of LAC, 20 cases of LSqCC and 20 cases of PEM. MUC4 immunostaining was done and assessed for each case. Results: There is high significant statistical correlation between MUC4 expression with LAC, LSqCC, and PEM cases (P value $=0.0001$ ). $90 \%$ and $95 \%$ of $\mathrm{LAC}$ and $\mathrm{LSqCC}$ respectively are positive. All PEM cases are negative. The sensitivity and specificity of MUC4 in differentiating PEM from lung cancer including LAC
\end{abstract} and $\mathrm{LSqCC}$ are $92 \%$ and $100 \%$ respectively. Significant statistical correlation is found between MUC4 and histological subtype ( $\mathrm{P}$ value $<0.05)$, grade $(\mathrm{P}<0.01)$, and TNM stage $(\mathrm{P}<0.05)$ of LAC. Significant statistical inverse correlation is found between MUC4 expression and grade of LSqCC (P value < 0.05). Conclusions: MUC4 IHC can differentiate PEM from LAC and LSqCC. MUC4 expression increases with aggressive LAC, and increases with welldifferentiated LSqCC.

Keyword: lung cancer, pleural mesothelioma, MUC4.

Abbreviations: Lung adenocarcinoma (LAC), Lung squamous cell carcinoma (LSqCC), Pleural epithelioid mesothelioma (PEM). 


\section{Introduction:}

Lung carcinoma is the second most common cancer and the leading cause of cancer mortality worldwide, comprising almost $20 \%$ of all cancer deaths (1). In Egypt, lung cancer ranks the $5^{\text {th }}$ among all cancer, and according to the National Cancer Institute's Surveillance, primary lung tumors represented $2.23 \%$ of all primary malignant tumors diagnosed during the period 20002011 (2). Lung cancer is more common in males than females, and most people diagnosed at the age of 65 years or older. The main risk factor of lung malignancy is tobacco smoking (1).

Malignant mesothelioma is an aggressive neoplasm. In US, about 3,000 cases of mesothelioma are diagnosed each year (3). In Egypt, pleural mesothelioma is the most frequent primary pleural malignant tumor, and epithelioid subtype is the most common subtype forming $76.20 \%$ of all mesotheliomas (2). It occurs commonly in men due to more asbestos exposure (4). The median age at diagnosis of mesothelioma is 72 years $\mathbf{( 5 )}$.

Some of peripheral LAC or LSqCC present with pleurotropic growth like mesothelioma. The prognosis and management of epithelioid mesothelioma differ from lung carcinoma, so rapid correct diagnosis of mesothelioma is important (6).

MUC4 is a high-molecular weight glycoprotein which encoded by MUC4 gene. It consists of beta subunit which is ErbB2 ligand, and alpha subunit that is glycosylated and causes anti-adhesion effect to the cell, causing cell-cell and cellmatrix detachment (7). Expression of MUC4 was detected normally in respiratory tract epithelium, glandular epithelium of digestive tract, cervix, and prostate (8).

The aim of this study is to evaluate the IHC expression of MUC4 in LAC, $\mathrm{LSqCC}$ and PEM, and correlate the results with clinicopathological data, to clarify its diagnostic and prognostic role.

\section{Material and Methods:}

\section{Study Groups:}

This study was conducted retrospectively on selected formalin-fixed, paraffin-embedded biopsy specimens from 70 different lung and pleural lesions designated as; 30 cases of LAC (18 cases were excisional biopsy, and 12 cases were bronchoscopic biopsy), 20 cases of LSqCC (one case was excisional 
biopsy, and 19 cases were bronchoscopic biopsy), and 20 cases of PEM (all of them were open pleural biopsy). Cases were obtained through collection of archived formalin fixed, paraffin embedded blocks from Department of Pathology; Benha faculty of medicine, and Early Cancer Detection Unit of Benha University Hospital, during the period from 2011 to 2019. Cases were selected on basis of availability of demographic data and clinicopathological data. This research plan was approved by ethical committee.

\section{A-Histopathological Examination:}

Hematoxylin and eosin-stained slides on all cases were revised by two observers simultaneously to confirm the diagnosis and to classify the lesions. LAC cases were classified according to WHO 2015 into lepidic, acinar, papillary, solid, and invasive mucinous adenocarcinoma (IMA) (9), and were graded to well, moderate, and poorlydifferentiated tumors depending on conventional histological criteria (10). LSqCC cases were graded to well, moderate, and poorly-differentiated tumors according to percentage of keratinization. (11) LAC and LSqCC cases were staged by TNM staging to stage I, II, III, IV (12), and staging was applied only to 18 cases of LAC and one case of $\mathrm{LSqCC}$ which were excisional biopsies. PEM cases were graded as grade I, II, and III according to Threetier Nuclear Grading System depending on nuclear atypia and mitotic count (13) and were staged by TNM staging to stage I, II, III, IV (14).

\section{B-Immunohistochemical Procedure:}

According to manufacture instructions, 3-4 micron tissue sections were obtained from formalin-fixed, paraffin-embedded tissue blocks on coated slides. After xylene deparaffinization, the sections were rehydrated in descending grades of alcohol then in distilled water. Antigen retrieval was done by using $10 \mathrm{mmol} / \mathrm{L}$ citrate monohydrate buffers ( $\mathrm{pH}$ 6.0) and heated for 15 minutes in microwave. The endogenous peroxidase activity was inactivated by incubation in $3 \%$ hydrogen peroxide $(\mathrm{H} 2 \mathrm{O} 2)$ for 15 minutes then washing by distilled water. Slides then were immunostained for MUC4 polyclonal antibody (Chongqing, 400039, China)) at a dilution of 1:50, at room temperature overnight. Immunodetection was executed using a standard labeled streptavidin-biotin system (Dako Cytomation, Denmark, A/S). Immunoreaction was seen by adding $\mathrm{DAB}$ as a chromagen. Counterstaining of slides 
was done with Mayer hematoxylin for 1-2 minutes and dehydrated in ascending alcohol. The slides were cleared in xylene for three changes and cover slides were applied.

\section{Negative \& positive controls:}

Apparently normal bronchial epithelium at resected surgical margins for lung carcinoma cases was used as positive control for MUC4. For negative controls, omitting the primary antibody and replacing it with normal rabbit serum IgG.

\section{Immunostaining evaluation:}

MUC4 expression was detected as cytoplasmic or cytoplasmic and membranous homogeneous brown coloration. Immunoreactivity was assessed by evaluating the extent and intensity of stained cells (15) (16). As regard the extent of staining, percentage of positive cells was scored as: $0=$ no positive cells, $1=<10 \%$ of positive cells, $2=10-50 \%$ positive cells, $3=$ $51-80 \%$ positive cells, $4=>80 \%$ positive cells. Intensity of staining was scored as: $0=$ no colour reaction, $1=$ mild reaction, $2=$ moderate reaction, $3=$ intense reaction. An immunoreactive score (IRS) which consecrate a range of $0-12$ was calculated by multiplication of percentage of positive cells score (0-4), and intensity of staining score (0-3). Table (1) Then immunoreactivity was assessed according to IRS score as following: negative: IRS score was 0-1, mild positive: IRS score was 2-3, moderate positive: IRS score was 4-8, strong positive: IRS score was 9-12 (17). Expression of MUC4 was then correlated with histopathological data in studied cases.

Table 1: IRS and IRS-Classification Scoring System.

\begin{tabular}{lll}
\hline Percentage of positive cells $(\mathbf{0 - 4})$ & \multicolumn{1}{c}{ Intensity of staining (0-3) } & \multicolumn{1}{c}{$\begin{array}{c}\text { IRS Score } \\
\text { (Multiplication of A and B) }\end{array}$} \\
\hline $0=$ no positive cells & $0=$ no colour reaction & $0-1=$ negative \\
$1=<10 \%$ of positive cells & $1=$ mild reaction & $2-3=$ mild \\
$2=10-50 \%$ positive cells & $2=$ moderate reaction & $4-8=$ moderate \\
$3=51-80 \%$ positive cells & $3=$ intense reaction & $9-12=$ strongly positive \\
$4=>80 \%$ positive cells & & \\
\hline
\end{tabular}

IRS: Immunoreactive score

Statistical analysis: Results were analyzed by SPSS (version 16) statistical package for Microsoft windows. The Pearson correlation coefficient was used for statistical analysis.
$\mathrm{P}$ value $<0.05$ was considered statistically significant, and highly statistically significant when it was $<0.01$. 


\section{Results:}

\section{1-Clinical result:}

Significant statistical correlation is found between smoking and different histological

types of studied cases ( $\mathrm{P}$ value $<0.05)$. No significant statistical correlation is found between gender and different histological types of studied cases $(\mathrm{P}$ value $>0.05)$ as shown in table (2).

Table 2: Correlation between different studied cases and clinical data:

\begin{tabular}{|c|c|c|}
\hline Different studied cases & \multicolumn{2}{|c|}{ Mean age } \\
\hline LAC & \multicolumn{2}{|c|}{61 year } \\
\hline $\mathrm{LSqCC}$ & \multicolumn{2}{|c|}{61.6 year } \\
\hline PEM & \multicolumn{2}{|c|}{66.8 year } \\
\hline & \multicolumn{2}{|c|}{ Gender } \\
\hline & Male & Female \\
\hline LAC & $50 \%$ & $50 \%$ \\
\hline $\mathrm{LSqCC}$ & $80 \%$ & $20 \%$ \\
\hline \multirow[t]{3}{*}{ PEM } & $65 \%$ & $35 \%$ \\
\hline & \multicolumn{2}{|c|}{$\begin{array}{c}\mathrm{P} \text { value }=0.2 \\
\text { Smoking status }\end{array}$} \\
\hline & Smoker & Non smoker \\
\hline LAC & $50 \%$ & $50 \%$ \\
\hline $\mathrm{LSqCC}$ & $75 \%$ & $25 \%$ \\
\hline PEM & $15 \%$ & $85 \%$ \\
\hline
\end{tabular}

\section{2-Histopathological result:}

Table 3: Histopathological features of different histological types of studied cases

\begin{tabular}{llc}
\hline & Variable & No(\%) \\
\hline Histological subtypes & Acinar adenocarcinoma & $15(50 \%)$ \\
Of LAC & Lipidic adenocarcinoma & $1(3.3 \%)$ \\
& Papillary adenocarcinoma & $4(13.3 \%)$ \\
& Solid adenocarcinoma & $6(20 \%)$ \\
Grade of LAC & Invasive mucinous adenocarcinoma & $4(13.3 \%)$ \\
& Grade II & $21(70 \%)$ \\
TNM stage of LAC & Grade III & $9(30 \%)$ \\
& Stage I & $4(22.2 \%)$ \\
& Stage II & $6(33.3 \%)$ \\
& Stage II & $3(16.7 \%)$ \\
Grade of LSqCC & Stage IV & $5(27.8 \%)$ \\
& Grade II & $8(40 \%)$ \\
Grade of PEM & Grade III & $12(60 \%)$ \\
& Grade I & $5(25 \%)$ \\
TNM stage of PEM & Grade II & $10(50 \%)$ \\
& Grade III & $5(25 \%)$ \\
& Stage I & $0(0 \%)$ \\
& Stage II & $8(40 \%)$ \\
& Stage III & $11(55 \%)$ \\
\hline
\end{tabular}

N.B: As regard LSqCC, only one case was excisional biopsy and it was stage I, while the other 19 cases were bronchoscopic biopsy so TNM staging cannot be applied. 
Benha medical journal, vol. 39, Special issue (academic), 2022

Table 4: Correlation between histopathological subtype and TNM stage of LAC

\begin{tabular}{|c|c|c|c|c|c|}
\hline \multirow{3}{*}{$\begin{array}{l}\text { Histopathological } \\
\text { subtype of LAC }\end{array}$} & \multirow[t]{2}{*}{ Total } & \multicolumn{4}{|c|}{ TNM stage of LAC } \\
\hline & & Stage I & Stage II & Stage III & Stage IV \\
\hline & NO. (\%) & NO. (\%) & NO. (\%) & NO. (\%) & NO. (\%) \\
\hline Acinar & $9(50 \%)$ & $3(33.3 \%)$ & $3(33.3 \%)$ & $1(11.1 \%)$ & $2(22.2 \%)$ \\
\hline Papillary & $3(16.7 \%)$ & $1(33.3 \%)$ & $2(66.7 \%)$ & $0(0 \%)$ & $0(0 \%)$ \\
\hline Solid & $2(11.1 \%)$ & $0(0 \%)$ & $0(0 \%)$ & $1(50 \%)$ & $1(50 \%)$ \\
\hline Lipidic & $1(5.5 \%)$ & $0(0 \%)$ & $1(100 \%)$ & $0(0 \%)$ & $0(0 \%)$ \\
\hline Invasive mucinous & $3(16.7 \%)$ & $0(0 \%)$ & $0(0 \%)$ & $1(33.3 \%)$ & $2(66.7 \%)$ \\
\hline Total & $18(100 \%)$ & $4(22.2 \%)$ & $6(33.3 \%)$ & $3(16.7 \%)$ & $5(27.8 \%)$ \\
\hline & & P Value & & & \\
\hline
\end{tabular}

There is a significant statistical correlation between histopathological subtype and TNM stage of the LAC ( $\mathrm{P}$ value $<0.05)$. No significant statistical correlation is found between grade of LAC and histopathological subtype or between grade and TNM stage of LAC $(\mathrm{P}$ value $>0.05)$.

\section{3-Immunohistochemical results:}

There was high significant statistical correlation between MUC4 expression and different studied types $(\mathrm{P}$ value $=0.0001)$, as all cases of PEM were negative, while $90 \%$, 95\% of LAC and LSqCC respectively were positive. Regarding LAC, MUC4 expression is significantly statistical correlated with histological subtype, grade, and TNM stage ( $\mathrm{P}$ value $<0.05$ ), while in $\mathrm{LSqCC}$, there is significant statistical inverse correlation between MUC4 expression and grade (P value $<0.05$ ). Table (5) (Figure 1; a, b, c, d) 
Table 5: Correlation between MUC4 and different clinicopathological variables of studied cases

MUC4 expression

\begin{tabular}{|c|c|c|c|c|c|c|}
\hline \multicolumn{2}{|c|}{ Clinico-pathological variants } & \multirow{3}{*}{$\begin{array}{c}\text { Negative } \\
10 \%\end{array}$} & \multirow{3}{*}{$\begin{array}{c}\text { Mild } \\
36.7 \%\end{array}$} & \multirow{3}{*}{$\begin{array}{c}\text { Moderate } \\
20 \%\end{array}$} & \multirow{3}{*}{$\begin{array}{l}\text { Strong } \\
33.3 \%\end{array}$} & \multirow{3}{*}{$\begin{array}{c}\text { P value } \\
0.0001\end{array}$} \\
\hline & Lung & & & & & \\
\hline & adenocarcinoma & & & & & \\
\hline \multirow[t]{5}{*}{ Studied cases } & $\begin{array}{l}\text { Lung squamous cell } \\
\text { carcinoma }\end{array}$ & $5 \%$ & $45 \%$ & $35 \%$ & $15 \%$ & $\begin{array}{c}\text { Highly } \\
\text { significant }\end{array}$ \\
\hline & $\begin{array}{l}\text { Pleural epithelioid } \\
\text { mesothelioma }\end{array}$ & $100 \%$ & $0 \%$ & $0 \%$ & $0 \%$ & \\
\hline & $\begin{array}{l}\text { Acinar } \\
\text { adenocarcinoma }\end{array}$ & $20 \%$ & $46.7 \%$ & $13.3 \%$ & $20 \%$ & \\
\hline & Papillary & $0 \%$ & $75 \%$ & $25 \%$ & $0 \%$ & \\
\hline & adenocarcinoma & & & & & $<0.05$ \\
\hline \multirow[t]{3}{*}{$\begin{array}{l}\text { Histological subtype of } \\
\text { lung adenocarcinoma }\end{array}$} & $\begin{array}{l}\text { Solid } \\
\text { adenocarcinoma }\end{array}$ & $0 \%$ & $0 \%$ & $0 \%$ & $100 \%$ & Significant \\
\hline & $\begin{array}{l}\text { Lipidic } \\
\text { adenocarcinoma }\end{array}$ & $0 \%$ & $0 \%$ & $100 \%$ & $0 \%$ & \\
\hline & $\begin{array}{l}\text { Invasive mucinous } \\
\text { adenocarcinoma }\end{array}$ & $0 \%$ & $25 \%$ & $50 \%$ & $25 \%$ & \\
\hline \multirow{2}{*}{$\begin{array}{l}\text { Grade of lung } \\
\text { adenocarcinoma }\end{array}$} & Grade II & $14.3 \%$ & $47.6 \%$ & $28.6 \%$ & $9.5 \%$ & 0.0001 \\
\hline & Grade III & $0 \%$ & $11.1 \%$ & $0 \%$ & $88.9 \%$ & $\begin{array}{c}\text { Highly } \\
\text { significant }\end{array}$ \\
\hline \multirow[t]{4}{*}{$\begin{array}{l}\text { TNM stage of lung } \\
\text { adenocarcinoma }\end{array}$} & Stage I & $25 \%$ & $75 \%$ & $0 \%$ & $0 \%$ & $<0.05$ \\
\hline & Stage II & $0 \%$ & $50 \%$ & $33.3 \%$ & $16.7 \%$ & Significant \\
\hline & Stage III & $0 \%$ & $66.7 \%$ & $0 \%$ & $33.3 \%$ & \\
\hline & Stage IV & $0 \%$ & $20 \%$ & $40 \%$ & $40 \%$ & \\
\hline \multirow{2}{*}{$\begin{array}{l}\text { Grade of lung } \\
\text { squamous cell } \\
\text { carcinoma }\end{array}$} & Grade II & $0 \%$ & $12.5 \%$ & $62.5 \%$ & $25 \%$ & \\
\hline & Grade III & $8.3 \%$ & $66.7 \%$ & $16.7 \%$ & $8.3 \%$ & $\begin{array}{c}<0.05 \\
\text { Significant }\end{array}$ \\
\hline
\end{tabular}




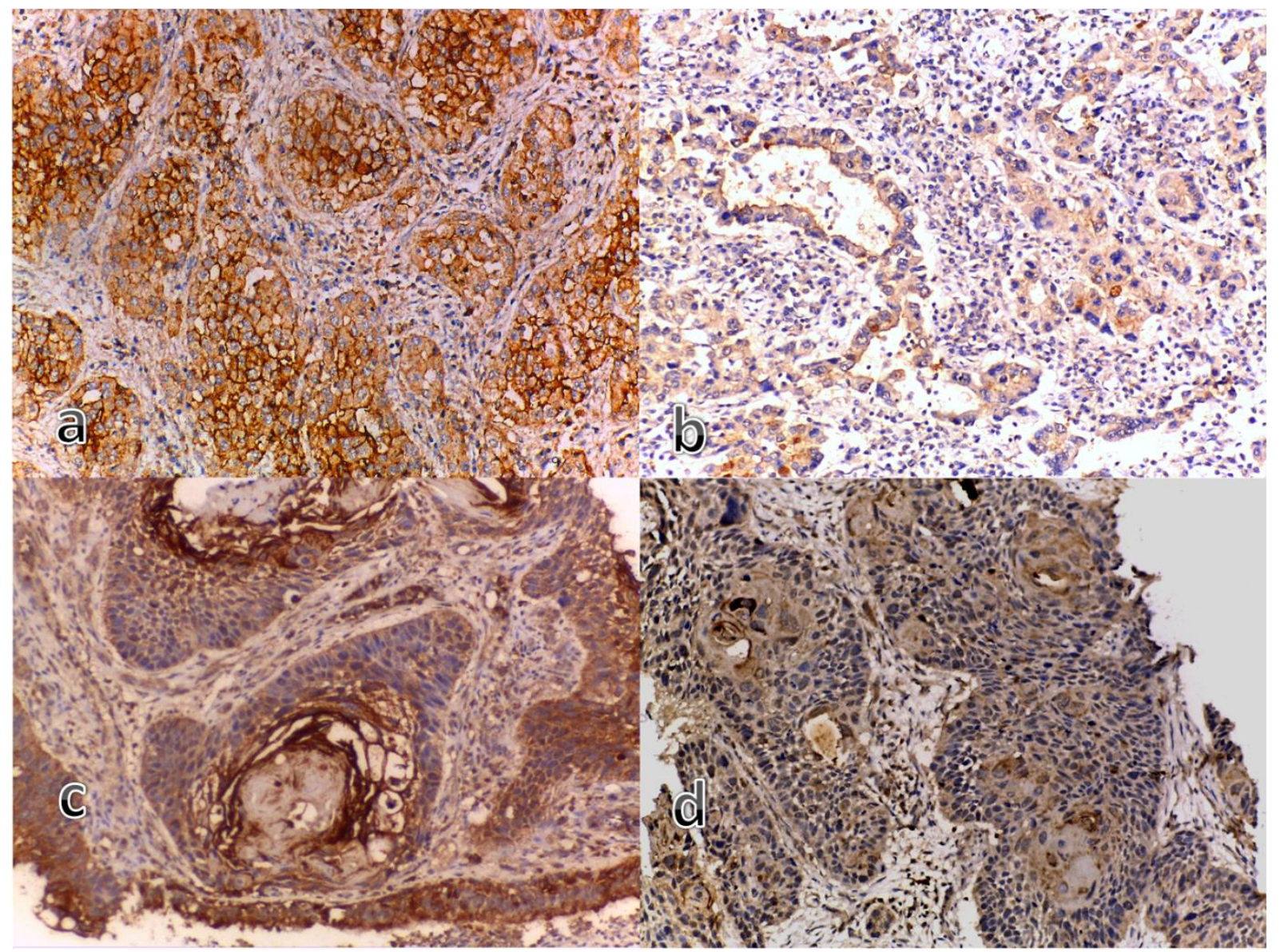

Figure (1): a) Lung adenocarcinoma, solid subtype, grade III, showing strong positive MUC4 IHC, with cytoplasmic and membranous expression. (ABC X 200). b) Lung adenocarcinoma, acinar subtype, grade II, showing moderate positive MUC4 IHC, with cytoplasmic and membranous expression. (ABC X 200). c) Lung squamous cells carcinoma; grade II, showing strong positive MUC4 IHC, with cytoplasmic and membranous expression. (ABC X 200). d) Lung squamous cells carcinoma; grade II, showing moderate positive MUC4 IHC, with cytoplasmic and membranous expression. (ABC X200)

\section{Discussion:}

Lung cancer is the second most common cancer and leading cause of cancer mortality worldwide. In Egypt, primary lung tumors represented $2.23 \%$ of all primary malignant tumors. (1) \& (2). Malignant pleural mesothelioma is an aggressive malignant tumor. In US, about 3,000 new cases of mesothelioma are diagnosed each year. In Egypt, pleural mesothelioma is the commonest primary pleural malignancy forming 53.08\%. (2) \& (3).

This retrospective study was done on 70 different lung and pleural cases including LAC, LSqCC, and PEM. MUC4 was immunohistochemically stained and evaluated for each case. Then its expression 
was correlated with different clinical and histopathological variables.

Regarding age distribution in our study, the mean age of LAC, LSqCC, and PEM cases was 61, 61.6, 66.8 year respectively. Maximum age group for LAC and LSqCC was in the seventh decade, while for PEM, it was in the eighth decade. This is close to a study reported that the mean age of lung cancer was 60 years (18). Other study reported that mesothelioma incidence increases in the $\geq 75$-year age group (19). This may be explained by that mesothelioma occurs after latency periods range from 20 to more than 50 years after asbestos exposure (20).

In our study, there was equal gender distribution in LAC, while $80 \%$ of LSqCC cases showed male predominance. Other study explained male predominance in LSqCC could be due to majority of smoker patients are men (21). 65\% of pleural epithelioid mesothelioma cases showed a male predominance. Male predominance in pleural mesothelioma is explained by occupational exposure to asbestos in male (22).

There was significant statistical correlation between smoking and different histological type of studied cases. $75 \%, 50 \%$, and $15 \%$ of studied LSqCC, LAC, and PEM cases respectively were smokers. This runs parallel with a study reported that smoking is the main cause of lung carcinoma (23).

In our study, there was a significant statistical correlation between histopathological subtype and TNM stage of LAC $(\mathrm{P}$ value $=0.03)$. The acinar, papillary, and lipidic subtypes associated with stage I and II, while solid and mucinous subtype associated with advanced stage (Stage III and IV). This is close to a study in which nodal metastasis was high in solid adenocarcinoma and distant metastasis was more in mucinous and solid types, while acinar, lipidic, and papillary subtypes have lower nodal and distant metastasis risk (24). Some studies reported that invasive mucinous type presented with advanced stage (25) (26). Other study reported that solid adenocarcinomas were significantly correlated with advanced stage, and lipidic subtype had low TNM stage (27).

In contrast, other study reported that invasive mucinous subtype was associated with low stage (28). This could be explained by that invasive mucinous is not aggressive neoplasm as it has common KRAS mutation, but rare TP53 mutation, and low mutation burden overall (29). 
MUC4 is a high-molecular weight glycoprotein which encoded by MUC4 gene which is located at chromosomal locus 3q29. Beta subunit acts as a ligand for HER2 (30). HER2 binds to EGF-like domain of MUC4 then activates AKT, MAPK, and ERK pathways causing cell proliferation, survival, and invasion (7).

The current study evaluated MUC4 expression in LAC, LSqCC, and PEM aiming to evaluate its diagnostic role in distinguishing PEM from LAC and LSqCC, and evaluate the relation between MUC4 expression and aggressiveness of LAC, and $\mathrm{LSqCC}$.

Our study revealed a highly significant statistical relation between the MUC4 expression and different histological subtype of studied cases $(\mathrm{P}$ value $=0.0001)$. Out of the studied LAC cases, $90 \%$ were positive, while $95 \%$ of studied LSqCC cases were positive. All studied cases $(100 \%)$ of PEM were negative.

This result runs parallel to a study that described the value of MUC4 immunostaining for differentiation between reactive mesothelial cell and metastatic adenocarcinoma of variable primary sites including lung adenocarcinoma in pleural and peritoneal effusions. $88.4 \%$ of metastatic lung adenocarcinoma cases were positive MUC4, while only $9.8 \%$ of reactive mesothelial cells cases were positive (31).

This study is parallel to a study reported that MUC4 can differentiate epithelioid mesothelioma from $\mathrm{LAC}$ or $\mathrm{LSqCC}$, as MUC4 expression was positive in $83.3 \%$ of lung adenocarcinoma, $89.3 \%$ of $\mathrm{LSqCC}$, and 0\% of PEM (16).

This can be explained by that the mesothelial cells, which have mesodermal origin, cannot express apomucins, which expressed in adenocarcinoma of variable origins and normal tissues which arise from endoderm (32).

This current study showed significant statistical correlation between different histological subtype of LAC and MUC4 expression ( $\mathrm{P}$ value $<0.05)$. 100\% of solid cases were strong positive for MUC4, while the mild positivity was detected in $46.7 \%$ of acinar and $75 \%$ of papillary subtypes. This can be explained by that MUC4 inhibits cell differentiation which mediated by MUC4 induced ErbB2 and ErbB3 phosphorylation. This finding runs parallel to a study which reported that MUC4 tend to be positive in solid adenocarcinoma (15).

In our work, there was highly significant statistical correlation between the 
histological grading of LAC and MUC4 expression $(\mathrm{P}$ value $=0.0001) .47 .1 \%$ of grade II lung adenocarcinoma were mild positive, while $88.9 \%$ of grade III lung adenocarcinoma were strong positive. This finding runs parallel to a study which reported that MUC4 expression increases with poorly differentiated adenocarcinoma (15).

The current study showed significant statistical inverse correlation between the histological grading of $\mathrm{LSqCC}$ and MUC4 expression ( $\mathrm{P}$ value $<0.05)$ as MUC4 expression was lower in grade III LSqCC. This runs parallel with a study which reported that, MUC4 was highly expressed in well-differentiated squamous cell carcinoma cells located in the center of tumor nests and in squamous pearls, and weak positive or negative in periphery and less-differentiated cells of the nests (33). Other study reported that MUC4 gene expression during differentiation of cultured airway epithelial cells was high in welldifferentiated cells compared to lowdifferentiated cells (34).

Our current study showed significant statistical correlation between the TNM stage of LAC and MUC4 expression ( $\mathrm{P}$ value $<0.05)$, as expression increased with high stage. This finding is close to a study 73 which reported that over-expression of MUC4 was significantly correlated with invasion, nodal metastasis, and high stage (35). While other study showed that MUC4 expression was insignificantly correlated with lung adenocarcinoma stage (15).

The oncogenic role of MUC4 can be explained by that beta subunit acts as ligand for HER2, and when HER2 bind with EGFlike domain of MUC4, it activates AKT, MAPK, and ERK pathways causing cell proliferation, apoptosis inhibition, and invasion (36). HER2 cause apoptosis inhibition by deactivation of protein $\mathrm{Bad}$ causing activation of antiapoptotic Bcl-XL and Bcl-2 (37). MUC4 increases epithelialto-mesenchymal transition, leading to tumor invasion (38).

In contrast, a study revealed that lower MUC4 expression in NSCLC was associated with higher stage, and explained that MUC4 has tumor suppressor role in NSCLC as it inhibits proliferation and metastasis of lung carcinoma (39). Also other study reported that MUC4 expression was significantly high in stage I and II lung adenocarcinoma, and lower expression was detected in adenocarcinoma with nodal metastasis (33).

Such divergent results regarding MUC4 correlations with different variables 
explained by that MUC4 may be an indicator for differentiation or mediator for tumor growth and aggressiveness. MUC4 is ligand for ErbB2, and it causes phosphorylation of ErbB2, and there are two pathways of ErbB2 tyrosine phosphorylation by MUC4 and prognostic role of MUC4 depends on which of the two pathways is working.

The first pathway: ErbB2-MUC4 complex phosphorylation may happen without heterodimerization of other ErbB2 receptor families, and with absence of other soluble ligand that causes phosphorylation of ErbB2 receptor tyrosine kinase only at special site 1248, that results in increasing p27 expression (cyclin dependent kinase inhibitor) leading to cell cycle arrest and promoting tumor differentiation, and this pathway associated with better prognosis.

The second pathway: Alternately MUC4 can complex with ErbB2 and form heterodimer with ErbB3 with presence of neurogulin. MUC4-ErbB2-ErbB3neurogulin complex causes high degree phosphorylation of ErbB2 and ErbB3 leading to inactivation of p27 and activation of MAPK and PI3K dependent AKT pathway, leading to inhibition of differentiation and increasing cell proliferation causing progression and worse prognosis of tumors (40).

\section{Conclusion:}

The present work reveals that MUC4 IHC may help to differentiate pleural epithelioid mesothelioma from lung adenocarcinoma and lung squamous cell carcinoma. The study reveals that MUC4 is a good negative marker for PEM. As regarding LAC, MUC4 expression increases with more aggressive tumors which have solid predominant histological pattern, high grade, and advanced stage, so it could be considered as an independent prognostic factors.

\section{References:}

1. Siegel RL, PhD MK. AJD. Cancer statistics, 2018. Ca A Cancer J Clin. 2018;68(1):11.

2. Mokhtar N, Salama A, Badawy O, Khorshed E, Mohamed G, Ibrahim M. Cancer Pathology Registry A 12-year Registry 2000-2011. National Cancer Institute. 2016;13:192-208

3. Carbone M, Adusumilli PS, Alexander Jr HR, Baas P, Bardelli F, Bononi A, et al. Mesothelioma: scientific clues for prevention, diagnosis, and therapy. CA: a cancer journal for clinicians. 2019 Sep;69(5):402-29.

4. Kukuyan AM, Sementino E, Kadariya Y, Menges $\mathrm{CW}$, Cheung $\mathrm{M}$, Tan $\mathrm{Y}$, et al. Inactivation of Bap1 cooperates with losses of $\mathrm{Nf} 2$ and Cdkn2a to drive the development of pleural malignant mesothelioma in conditional mouse models. Cancer research. 2019 Aug 15;79(16):4113-23.

5. Verma V, Wegner RE, Ludmir EB, Hasan S, Colonias A, Grover S, et al. Management of malignant pleural mesothelioma in the elderly 
population. Annals of surgical oncology. 2019 Aug 15;26(8):2357-66.

6. Galateau-Salle F, Churg A, Roggli V, Travis WD, for Tumors WH. The 2015 World Health Organization classification of tumors of the pleura: advances since the 2004 classification. Journal of thoracic oncology. 2016 Feb $1 ; 11(2): 142-54$

7. Xia P, Choi AH, Deng Z, Yang Y, Zhao J, Wang $\mathrm{Y}$, et al. Cell membrane-anchored MUC4 promotes tumorigenicity in epithelial carcinomas. Oncotarget. 2017 Feb 21;8(8):14147.

8. Schmuck RB, de Carvalho-Fischer CV, Neumann C, Pratschke J, Bahra M. Distal bile duct carcinomas and pancreatic ductal adenocarcinomas: postulating a common tumor entity. Cancer medicine. 2016 Jan;5(1):88-99.

9. Lantuejoul S, Rouquette I, Brambilla E, Travis WD. New WHO classification of lung adenocarcinoma and preneoplasia. InAnnales de pathologie 2016 Jan 11 (Vol. 36, No. 1, pp. 514)..

10. Yasukawa M, Ohbayashi C, Kawaguchi T, Kawai N, Nakai T, Sawabata N, et al. Analysis of Histological Grade in Resected Lung-invasive Adenocarcinoma. Anticancer research. 2019 Mar 1;39(3):1491-500.

11. Kadota K, Nitadori JI, Woo KM, Sima CS, Finley DJ, Rusch VW, et al. Comprehensive pathological analyses in lung squamous cell carcinoma: single cell invasion, nuclear diameter, and tumor budding are independent prognostic factors for worse outcomes. Journal of Thoracic Oncology. 2014 Aug 1;9(8):1126-39.

12. Goldstraw P, Chansky K, Crowley J, RamiPorta R, Asamura H, Eberhardt WE, et al. The IASLC lung cancer staging project: proposals for revision of the TNM stage groupings in the forthcoming (eighth) edition of the TNM classification for lung cancer. Journal of Thoracic Oncology. 2016 Jan 1;11(1):39-51.

13. Rosen LE, Karrison T, Ananthanarayanan V, Gallan AJ, Adusumilli PS, Alchami FS, et al.
Nuclear grade and necrosis predict prognosis in malignant epithelioid pleural mesothelioma: a multi-institutional study. Modern Pathology. 2018 Apr;31(4):598-606.

14. Proto C, Signorelli D, Mallone S, Prelaj A, Russo GL, Imbimbo M, et al. The Prognostic Role of TNM Staging Compared With Tumor Volume and Number of Pleural Sites in Malignant Pleural Mesothelioma. Clinical Lung Cancer. 2019 Nov 1;20(6):e652-60.

15. Rokutan-Kurata M, Yoshizawa A, Sumiyoshi S, Sonobe M, Menju T, Momose M, et al. Lung adenocarcinoma with MUC4 expression is associated with smoking status, HER2 protein expression, and poor prognosis: clinicopathologic analysis of 338 cases. Clinical lung cancer. 2017 Jul 1;18(4):e273-81.

16. Mawas AS, Amatya VJ, Kushitani K, Kai Y, Miyata Y, Okada M, et al. MUC4 immunohistochemistry is useful in distinguishing epithelioid mesothelioma from adenocarcinoma and squamous cell carcinoma of the lung. Scientific Reports. 2018 Jan 9;8(1):1-8.

17. Abidullah $\mathrm{M}$, Nahar $\mathrm{P}$, Ahmed $\mathrm{SA}$ Expression of MUC4 in Oral Dysplastic Epithelium. International Journal of Pharmaceutical Investigation. 2019 Aug 13;9(2):85-8.

18. Jeon JM, Lee HW, Park JY, Jung HR, Hwang I, Kwon SY, Choe MS, Kang YN, Kim SP, Lee SS, Choi WI. Expression of MUC1 and MUC4 and Its Prognostic Significance in NonSmall Cell Lung Carcinoma. Korean Journal of Pathology. 2010 Aug 1;44(4):397-403.

19. Kerger BD. Longevity and pleural mesothelioma: age-period-cohort analysis of incidence data from the Surveillance, Epidemiology, and End Results (SEER) Program, 1973-2013. BMC research notes. 2018 Dec 1;11(1):337.

20. Lin RT, Chang YY, Wang JD, Lee LJ. Upcoming epidemic of asbestos-related malignant pleural mesothelioma in Taiwan: a prediction of incidence in the next 30 years. Journal of the 
Formosan Medical Association. 2019 Jan 1;118(1):463-70.

21. Wang BY, Huang JY, Chen HC, Lin CH, Lin SH, Hung $\mathrm{WH}$, et al. The comparison between adenocarcinoma and squamous cell carcinoma in lung cancer patients. Journal of Cancer Research and Clinical Oncology. 2020 Jan 1;146(1):43-52.

22. Keshava HB, Tang A, Siddiqui HU, Raja S, Raymond DP, Bribriesco A, et al. Largely Unchanged annual incidence and overall survival of pleural mesothelioma in the USA. World Journal of Surgery. 2019 Dec 1;43(12):3239-47.

23. O'Keeffe LM, Taylor G, Huxley RR, Mitchell P, Woodward M, Peters SA. Smoking as a risk factor for lung cancer in women and men: a systematic review and meta-analysis. BMJ open. 2018 Oct 1;8(10):e021611.

24. $\mathrm{Xu} \mathrm{L}$, Tavora F, Burke A. Histologic features associated with metastatic potential in invasive adenocarcinomas of the lung. The American journal of surgical pathology. $2013 \mathrm{Jul}$ 1;37(7):1100-8.

25. Dacic S. Pros: the present classification of mucinous adenocarcinomas of the lung. Translational Lung Cancer Research. 2017 Apr;6(2):230.

26. Kadota K, Yeh YC, D’Angelo SP, Moreira AL, Kuk D, Sima CS, et al. Associations between mutations and histologic patterns of mucin in lung adenocarcinoma: invasive mucinous pattern and extracellular mucin are associated with KRAS mutation. The American journal of surgical pathology. 2014 Aug;38(8):1118.

27. Zhao Y, Wang R, Shen X, Pan Y, Cheng C, Li Y, et al. Minor components of micropapillary and solid subtypes in lung adenocarcinoma are predictors of lymph node metastasis and poor prognosis. Annals of surgical oncology. 2016 Jun 1;23(6):2099-105.

28. Moon SW, Choi SY, Moon MH. Effect of invasive mucinous adenocarcinoma on lung cancer-specific survival after surgical resection: a population-based study. Journal of thoracic disease. 2018 Jun;10(6):3595.

29. Shim HS, Zheng Z, Liebers M, Cha YJ, Ho $\mathrm{QH}$, Onozato $\mathrm{M}$, et al. Unique genetic and survival characteristics of invasive mucinous adenocarcinoma of the lung. Journal of Thoracic Oncology. 2015 Aug 1;10(8):1156-62.

30. Vasseur R, Skrypek N, Duchene B, Renaud F, Martinez-Maqueda D, Vincent A, et al. The mucin MUC4 is a transcriptional and posttranscriptional target of K-ras oncogene in pancreatic cancer. Implication of MAPK/AP-1, $\mathrm{NF}-\mathrm{\kappa B}$ and RalB signaling pathways. Biochimica et Biophysica Acta (BBA)-Gene Regulatory Mechanisms. 2015 Dec 1;1849(12):1375-84.

31. Cho JS, Kim GE, Lee JS, Lee JH, Nam JH, Choi C. Diagnostic usefulness of MUC1 and MUC4 for distinguishing between metastatic adenocarcinoma cells and reactive mesothelial cells in effusion cell blocks. Acta cytologica. 2013;57(4):377-83. .

32. Llinares $\mathrm{K}$, Escande $\mathrm{F}$, Aubert $\mathrm{S}$, et al. Diagnostic value of MUC4 immunostaining in distinguishing epithelial mesothelioma and lung adenocarcinoma. Modern pathology; 17(2): 150157, 2004.

33. Lakshmanan I, Ponnusamy MP, Macha MA, Haridas D, Majhi PD, Kaur S, et al. Mucins in lung cancer: diagnostic, prognostic, and therapeutic implications. Journal of Thoracic Oncology. 2015 Jan 1;10(1):19-27.

34. Kwon KY, Ro JY, Singhal N, Killen DE, Sienko A, Allen TC, et al. MUC4 Expression in Non-Small Cell Lung Carcinomas: Relationship to Tumor Histology and Patient Survival. Archives of pathology \& laboratory medicine. 2007 Apr;131(4):593-8.

35. Huang X, Wang X, Lu SM, Chen C, Wang J, Zheng YY, et al. Clinicopathological and prognostic significance of MUC4 expression in cancers: evidence from meta-analysis. International journal of clinical and experimental medicine. 2015;8(7):10274.. 
36. Xia P, Choi AH, Deng Z, Yang Y, Zhao J, Wang Y, et al. Cell membrane-anchored MUC4 promotes tumorigenicity in epithelial carcinomas. Oncotarget. 2017 Feb 21;8(8):14147.

37. Tang J, Zhu Y, Xie K, Zhang X, Zhi X, Wang $\mathrm{W}$, et al. The role of the AMOP domain in MUC4/Y-promoted tumour angiogenesis and metastasis in pancreatic cancer. Journal of Experimental \& Clinical Cancer Research. 2016 Dec 1;35(1):91.

38. Nieto MA, Huang RY, Jackson RA, Thiery JP. EMT: 2016. Cell. 2016 Jun 30;166(1):21-45.
39. Majhi PD, Lakshmanan I, Ponnusamy MP, Jain M, Das S, Kaur S, et al. Pathobiological implications of MUC4 in non-small-cell lung cancer. Journal of Thoracic Oncology. 2013 Apr 1;8(4):398-407.

40. Sawant PR, Spadigam A, Dhupar A, Syed S, Carvalho K. Assessing the prognostic significance of MUC4 $\beta$ in mucoepidermoid carcinoma of the salivary glands: An immunohistochemical study. Heliyon. 2019 Nov 1;5(11):e02753.

To cite this article: Enas I. Elsayed, Heba H. Ahmed, Taghreed A. Abdelaziz, Samia A. Youssef. Significance of MUC4 in Epithelioid Mesothelioma of the Pleura, Adenocarcinoma and Squamous Cell Carcinoma of the Lung (Immunohistochemical Study). BMFJ 2022; 39(academic issue):63-77. 